\title{
Intellectualization of the Learning Process Based on Digital Technology
}

\author{
Sergey Neustroev ${ }^{1, a *}$, Irena Robert ${ }^{1, b}$ Mikhail Goncharov ${ }^{2, c}$ \\ 1 Institute of Education Management of the Russian Academy of Education, 105062, 16 \\ Zhukovskogo str., Moscow, Russia \\ 2 Moscow State Pedagogical University, 119991, 1/1 M. Pirogovskaya str., Moscow, Russia \\ anss@iuorao.ru, ${ }^{b}$ rena_robert@mail.ru, crust20@yandex.ru \\ ${ }^{*}$ Corresponding author
}

Keywords: digital technologies, national education, intellectualization, learning process, information interaction

\begin{abstract}
The influence of digital technologies on the development of national education is described. The possibilities of digital technologies in conditions of high-tech education are identified and described. The conditions for the intellectualization of the learning process in connection with the use of digital technologies in the information interaction of the subjects of the educational process with an interactive network resource are also reviewed.
\end{abstract}

\section{Introduction}

The current stage in the development of the information society and global mass communication network is characterized by the widespread adoption of digital information technologies and digital technologies. Currently, their use provides the ability to solve a huge number of different technological problems in small periods of time, providing fast and high-quality recovery of information. In addition, they allow for the introduction of new functions of a system without replacing its hardware, which ensures rapid adaptation of such a system to the constantly changing technological requirements [9].

The implementation of digital technologies generates "Digital Banking", which provides services to the population in conditions of remote access, information protection of these services, as well as various banking products. "Digital Economy" offers financial products, a digital payment platform, cryptocurrency, risk management, and investment. Biotechnology can solve the problems of hereditary diseases and disease prevention. Transport logistics provides high-speed transport and delivery of any goods at any distance. Digital technologies allow creating "Augmented Reality", which provides a combination of a virtual image on the screen [9]. Each object of the "Smart Home" connected to the global network is under the complete control of the owner while ensuring human interaction with certain objects and mechanisms at home, in the conditions of their management.

\section{Methodology}

In the conditions of high-tech education, the intellectualization of the learning process is based on the identification of digital technologies. Possible negative consequences of using digital technologies are revealed: users' content "blindness", information oversaturation, and information entropy. The substantive basis of the intellectualization of the learning process as one of the important conditions for the development of modern education is also reviewed in the paper.

\section{Results and discussion}

The implementation of digital technologies in high-tech education is built on the automated complexes based on high-tech devices, representing a system that recognizes specific learning situations occurring in a classrooms of an educational institution and responds to them accordingly, ensuring management of other objects' behavior in advance according to the developed algorithms $[2,5]$. At the same time, a user can program the equipment setting, send out educational materials, adjust the temperature, humidity in the 
classroom, control the lighting, ventilation and heating systems, video surveillance and alarm systems, and other equipment with one team. An important component for the functioning of such an educational institution is the availability of high-tech equipment, robot-like information systems and intelligent information systems for educational purposes $[7,8]$.

Despite the obvious advantages of using information systems that operate on the basis of digital technologies, the intellectualization of the learning process is currently not fully realized, by which we understand the provision of information interactive interaction between the subjects of the learning process by multivariate cause-and-effect analysis of data (information) on all aspects of this process with subsequent processing, visualization, obtaining, and storing results for their presentation and joint about the use of all subjects of the educational process.

At the same time, the technological level of modern information systems realizing the capabilities of digital technologies can provide a functional expansion of the conditions for the intellectualization of information interaction between the subjects of the learning process:

- Providing an audiovisual (sensory) contact of a student with the objects of the studied subject area (dialogue with feedback; modeling educational objects, processes, situations; their management);

- Ensuring the freedom to search for information ("library of experience", "library of methodological solutions", etc.) that implements the multidimensionality of studying the phenomenon under study, the historical situation, the educational plot;

- Studying the features of educational objects, processes in various aspects on the basis of various conceptual approaches, in various modes of educational activity, on the basis of which a student builds his/her assumptions, creates hypotheses, and draws conclusions;

- Providing the following: (i) a tool for the study of abstract images and concepts; (ii) a tool for modeling the objects under study, phenomena, both real and virtual; (iii) a tool simulation on the screen of real objects or processes; (iv) a design tool of the objective world, which is adequate to a certain content-methodical approach;

- Implementing the interaction with objects or participation in processes that find their display on the screen, the implementation of which is impossible in reality, but expedient from an educational and methodological point of view;

- Managing various virtual objects, processes in the implementation of information activities and information interaction;

- Creating screen spatial structures adequately for mental abstract interpretation and construction of object models, processes (both real and virtual) $[4,7]$.

The above allows us to generalize the substantive basis of the prospects for the development of the intellectualization of the learning process:

- Using an interface that does not require programming knowledge, providing users who have the right to receive information with access to detailed micro- and macro-data of a wide profile;

- Processing texts, audiovisual information, cartographic information, geospatial data, personal data, spatial and temporal data of geographic information systems while ensuring confidentiality of data processing and data exchange;

- Informational interaction between subjects of the educational process and all interested parties with an interactive source of authorized information on all aspects of the educational process in the institution;

- Using specialized statistics, such as all traditional statistical functions, as well as functions of taking into account students' achievements;

- Creating and demonstrating interactive visual reports and presentations while ensuring the flexibility of creating tables and managing them (interactive web visualizations embedded in the websites of educational institutions); 
- Generation of ever-increasing and expanding data volumes, their use in protecting large data sets and managing educational institution data for any period of time;

- Intellectual analysis of recorded data managed by the user, including analysis at the student level (group of students, educational institution), identification of the relationship of factors affecting the student's progress (group of students, educational institution);

- Implementing an automation equipment for rapid analysis of data for their accumulation for each student for any period of time, identifying trends in the demand for professional staff in the region, choosing subjects required for a particular profession;

- Operational analysis of data and information about each student, their progress in teaching, the demographic situation, ethnic, geographical, natural, and economic features of a particular region for the implementation of educational policy forecast $[1,4]$.

The use of digital technologies in education inevitably creates negative consequences $[11,12]$. First of all, they should include the so-called "information oversaturation of the user", as the lack of an individual's ability to analyze, identify structural links in the content of information when it is perceived. This state occurs when there is an excessive, uncontrolled use of information, with its chaotic search and no predetermined goals. Such unsystematic perception and use of information, especially presented in the audiovisual form, sometimes aggressively impose bright images on the user, preventing him/her from analyzing and identifying structural links in the content.

As a result of the information oversaturation of the user, he/she may experience a slower response to understanding the content of information being received and considered. This effect is often accompanied by "forgetting" the particular purpose of searching, which entails the desire to "travel" through information sites without a specific goal. This effect, manifested especially in children and adolescents with an immature psyche, is called the "informational entropy of the user". This is the attenuation of the meaningful response from an individual to the understanding of the content component of the information he or she receives.

More serious negative consequences of unsystematic, lengthy, and purposeless search and use of information without a specific goal, just for the sake of the information review process, for the sake of "virtual travel" in information flows leads to the so-called "users' content blindness", manifested in the impossibility achieving the awareness of the target, structurally-content, moral, and value component of information in its perception and use.

Possible negative consequences in the conditions of a long and intense search, consideration and use of information by an individual from arbitrarily chosen sources are manifested in a deliberate manipulation of human consciousness, in the emerging interdependence between the people, which is all due to the possibility of easily replacing a real communication partner with a "virtual partner."

\section{Conclusions}

Preventing possible negative effects described above in contemporary conditions of using digital technologies in education, including in a high-tech educational institution, is now reflected in a fairly large amount of scientific research in the following areas: information security of the user's identity; prevention of negative psychological, educational, and medical consequences; examination and certification of pedagogical products operating on the basis of digital technologies, which can be considered as the forerunner of the next stage of development of education in the conditions of using digital technologies.

\section{Acknowledgments}

The work was conducted in the 2nd quarter of 2018 as part of the State Assignment on the Program of Basic Scientific Research of the State Academies of Sciences for 2013-2020, approved by the Order of the Government of the Russian Federation of December 3, 2012 No. 2237-p, on the topic "Development of informatization of education in the context of information security of a person" (state registration № 14.07.00.20.01.04). 


\section{References}

[1] Kazakov, K. V., Neustroev, S. S., \& Simonov, A. V. (2014). Development strategy of a research organization operating in the field of informatization of education and science in the context of an innovative economy: new challenges, new solutions. Informatization of education and science, 2(22), pp. 3-11.

[2] Neustroev, S. S., \& Simonov, A. V. (2015). Innovative directions for the development of elearning. Man and Education, 3(44), pp. 9-15.

[3] Polyakov, V. P., (2016). Pedagogical support of information security aspects in the information training of university students. Pedagogical informatics, 4, pp. 37-47.

[4] Robert, I. V. (2017). Development of informatization of education in the conditions of intellectualization of activities and information security of subjects of the educational process. Pedagogical Informatics, 2, pp. 12-30.

[5] Robert, I. V. (2014). Theory and methods of education informatization (psychological, pedagogical, and technological aspects). Moscow, Russia: BINOM, Laboratory of Knowledge.

[6] Robert, I. V., \& Lavina, T. A. (Eds). (2011). Explanatory dictionary of terms of the conceptual apparatus of informatization of education. Moscow, Russia: BINOM. Laboratory of knowledge.

[7] Shikhnabiyeva, T. Sh., Ramazanova, I. M., \& Akhmedov, O. K. (2015). The use of intellectual methods and models to improve information systems for educational purposes. Monitoring: Science and Technology, 2(23), pp. 71-77.

[8] Shikhnabiyeva, T. Sh. (2011). Automating the process of learning and knowledge control using intelligent models of educational content. Pedagogical informatics, 5, pp. 27-31.

[9] Digital technology is the future of humanity. (n.d.). Retrieved from http://fb.ru/article/335698/tsifrovyie-tehnologii---eto-buduschee-chelovechestva.

[10] Igor Agamirzyan. (2017). The question arises, why does a person is needed in such a model. Retrieved from https://www.business-gazeta.ru/article/334149.

[11] Robert, I. V. et al. (2017). Forecast of the development of education informatization. Revista ESPACIOS, 38,40 .

[12] Robert, I. et al. (2016). Implementation of the Internet for educational purposes. In Smart Education and e-Learning (pp. 573-583). Berlin, Germany: Springer. 